\title{
Minimally Invasive Surgery of Spinal Extradural Arachnoid Cyst with High-Resolution Myelography: A Case Report
} \author{
of Korea \\ Corresponding author: Chung Kee Chough \\ Department of Neurosurgery, Yeouido St. \\ Mary's Hospital, The Catholic University \\ College of Medicine, 10, 63-ro, \\ Yeongdeungpo-gu, Seoul 07345, Republic \\ of Korea \\ Tel: $+82-2-3779-1187$ \\ Fax: +82-2-786-5809 \\ E-mail: chough@catholic.ac.kr
}

Jun Hong Lee, Seung Chan Yoo, Chung Kee Chough

Department of Neurosurgery, Yeouido St. Mary's Hospital, The Catholic University College of Medicine, Seoul, Republic

Received: September 15, 2020

Revised: September 27, 2020

Accepted: September 28, 2020
Spinal extradural arachnoid cyst (SEAC) is a rare disease, and symptomatic cases are even rarer. Symptoms can affect the quality of life of a patient due to compression myelopathy, radiculopathy, and pain. Treatment is often necessary for symptomatic SEACs, but no standard treatment has been established. We report a young symptomatic SEAC patient with both radiating leg pain and gait disturbance for several years. She was successfully treated with minimally invasive surgery through precise preoperative localization of the dural defect with high-resolution myelography and magnetic resonance imaging. Accurate and precise diagnosis is essential for successful minimally invasive surgical treatment of symptomatic SEAC.

Key Words: Arachnoid cysts; Fluoroscopy; Myelography; Minimally invasive surgical procedures; Spinal cord diseases

\section{INTRODUCTION}

Spinal extradural arachnoid cyst (SEAC) is a rare condition in which the arachnoid wall expands out of the dura, creating a cystic lesion that includes the cerebrospinal fluid (CSF). Depending on the location, neurologic symptoms such as myelopathy or radiculopathy can occur. The pathophysiology of the SEAC remains unclear ${ }^{11)}$. In some cases, SEAC can develop from arachnoid adhesion due to traumatic, inflammatory, infective, or iatrogenic causes (e.g., lumbar puncture, spine surgery $)^{1,10)}$. In these situations, adhesions within the arachnoid are supposed to form a one-way valve entrapping circulating $\mathrm{CSF}$, resulting in the formation of a SEAC ${ }^{4)}$.

Various surgical techniques have been introduced for treatment of SEAC. However, optimal treatment remains uncertain regarding removal of only dural defects or the entire SEAC ${ }^{4-6}$.

This report presents a case of successfully removed SEAC by repair of the dural defect only based on accurate location determination.

\section{CASE REPORT}

A 45-year-old woman presented with both leg pain that
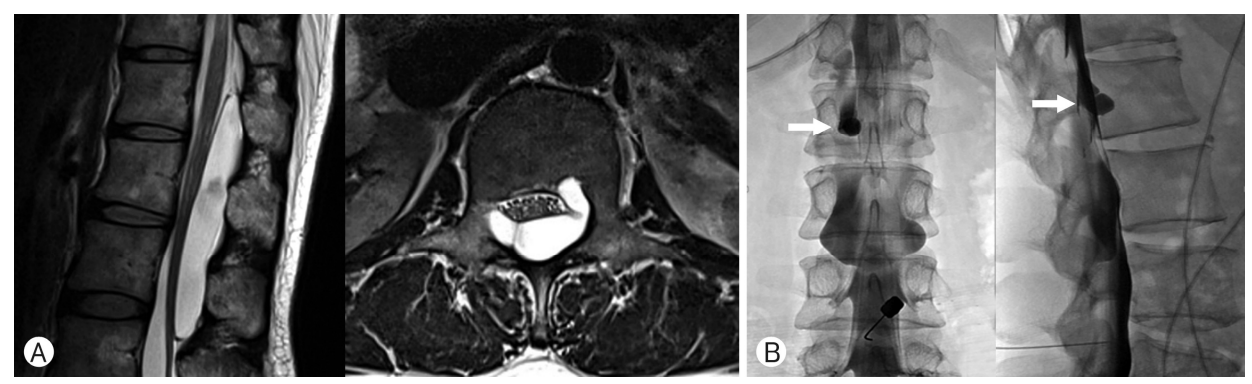

Fig. 1. (A) Preoperative magnetic resonance imaging showing a giant extradural arachnoid cyst from T10 to L2 level. (B) Fluoroscopic myelography showing the contrast leakage site on L1 level (arrow) in the left-side down lateral position. 
was exacerbated upon standing. The main symptoms were pain in both lower extremities and buttocks, with greater severity on the right side. She was treated several times by cyst aspiration, but it was unsuccessful. Magnetic resonance imaging (MRI) confirmed the extension of the giant arachnoid cyst from T12 to L3 level, resulting in thecal sac compression and a chronic lesion that thinned the surrounding structures such as the lamina and pedicle (Fig. 1A). It was suspected that was shunt flow causing one-way flow in the form of a check valve. Thus, myelography was implemented with real-time fluoroscopy at high resolution. We did not find any leaks in the

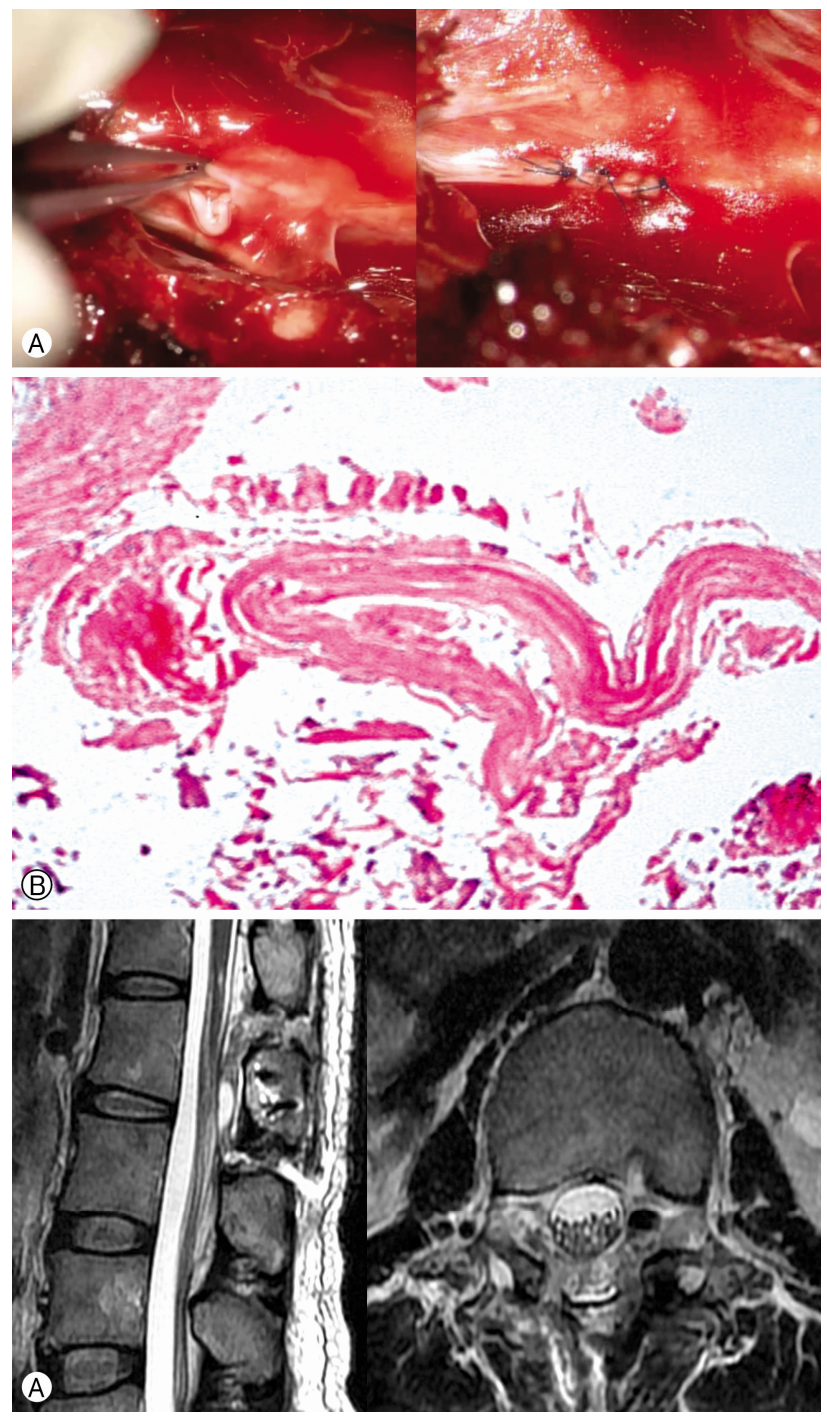

Fig. 2. (A) Intraoperative microscopic photograph showing a small dura defect and herniated rootlets at the side of an L1 vertebra. (B) Histologic findings of the arachnoid cystic wall with layered collagen fiber and lining cells, consistent with an arachnoid membrane. (C) Postoperative magnetic resonance imaging revealing complete resolution of spinal extradural arachnoid cyst and re-expansion of the arachnoid space. first trial, but we did localize a leakage point at the L1 level on the second attempt (Fig. 1B). The leakage flow was confirmed in the L1 level on imaging conducted with the patient in the left side-down lateral position.

To access the leakage site, we planned minimal laminectomy surgery. After checking the T12 to L1 levels in a prone position, a one-level laminectomy was performed. After removing the lamina, a large CSF fluid collection and arachnoid cyst wall were seen in the surgical field ${ }^{4,12)}$.

According to the categories of Nabors et al. ${ }^{9}$ (Table 1), the cyst was type Ia, without neural tissue. The cyst was partially removed, and the removed wall was sent for biopsy and pathologic confirmation ${ }^{6}$ (Fig. 2B).

A small dural defect was confirmed at the left mid-level of the L1 body, and some of the L1 rootlets protruded out and were serving as a plug for the created one-way valve ${ }^{1,8,10)}$ (Fig. 2A). This confirmed the leakage point, as identified on preoperative myelography.

The dural defect was simply sutured using prolene 7-0. After checking that there was no CSF leakage based on the Valsalva maneuver, the operation was performed after laminoplasty ${ }^{2,70)}$. Postoperative MRI showed improvement of compressive myelopathy (Fig. 2C).

The patient reported significantly improved symptoms with no complications in outpatient follow-up. Her quality of life was much improved.

\section{DISCUSSION}

SEACs can cause compressive myelopathy, radiculopathy, or other severe neurologic deficits such as paraplegia or paresthesia $^{11)}$. Researchers have hypothesized that dural defect acts as a one-way valve to result in the formation of an extradural arachnoid cyst $^{11}$.

Many surgical procedures can be performed for such cysts, including simple decompression, fenestration, subtotal or total cyst resection, or marsupialization ${ }^{4)}$. Eroglu et al. ${ }^{3)}$ reviewed 13 patients with spinal arachnoid cyst (SAC) who all underwent fenestration of the cyst wall into the subarachnoid space, inclu-

Table 1. Classification of extradural arachnoid cyst ${ }^{9}$

\begin{tabular}{cl}
\hline \hline Type & \multicolumn{1}{c}{ Description } \\
\hline I & Extradural meningeal cyst that contains no neural tissue \\
IA & Extradural arachnoid cysts \\
IB & Sacral meningoceles \\
II & Extradural meningeal cysts that contains spinal neural \\
& tissue \\
III & Spinal intradural meningeal cyst \\
\hline
\end{tabular}

[Reprinted from "Updated assessment and current classification of spinal meningeal cysts.", by Nabors MW, et al., 1988, J Neurosurg, 68, pp. 366-77. Copyright 2017 by the American Association of Neurological Surgeons. Reprinted with permission]. 
ding 5 total resections. Fam et al. ${ }^{4)}$ published a report on 22 adults with SAC in a single-center study including 6 patients with SEAC, and concluded that surgical exploration and complete resection followed by tight suturing of the fistula was the treatment of choice.

However, it is clear that side effects will increase with greater surgical extent. It is better to avoid multi-level laminectomy and fusion, as they can cause extensive muscle damage and T-L kyphosis ${ }^{2,5,6,12)}$. Several alternatives to minimally invasive surgical procedures have been reported such as selective laminectomy with fistula closure or imaging-guided aspiration.

To perform minimally invasive surgery, accurate localization is required. In our case, the most critical diagnostic procedure for accurate localization was myelography with real-time fluoroscopy $^{12)}$. There were many factors to consider, including the number of attempts, proper positioning, and intervention room in which a high-resolution imaging study can be performed. The dural defect was precisely located through leakage of contrast in the myelography, allowing repair of the dural defect with minimally invasive surgical treatment.

In conclusion, accurate localization of SEAC allows minimally invasive surgery. To avoid unnecessary extensive surgery, myelography with real-time fluoroscopy can be a useful diagnostic tool.

\section{CONFLICTS OF INTEREST}

No potential conflict of interest relevant to this article was reported.

\section{REFERENCES}

1. Cho HY, Lee SH, Kim ES, Eoh W: Symptomatic large spinal extradural arachnoid cyst: A case report. Korean J Spine 12:217220, 2015
2. Choi SW, Seong HY, Roh SW: Spinal extradural arachnoid cyst. J Korean Neurosurg Soc 54:355-358, 2013

3. Eroglu U, Bozkurt M, Kahilogullari G, Dogan I, Ozgural O, Shah KJ, et al.: Surgical management of spinal arachnoid cysts in adults. World Neurosurg 122:e1146-e1152, 2019

4. Fam MD, Woodroffe RW, Helland L, Noeller J, Dahdaleh NS, Menezes AH, et al.: Spinal arachnoid cysts in adults: Diagnosis and management. A single-center experience. J Neurosurg Spine 29:711-719, 2018

5. Funao H, Nakamura M, Hosogane N, Watanabe K, Tsuji T, Ishii $\mathrm{K}$, et al.: Surgical treatment of spinal extradural arachnoid cysts in the thoracolumbar spine. Neurosurgery 71:278-284; discussion 284, 2012

6. Lee CH, Hyun SJ, Kim KJ, Jahng TA, Kim HJ: What is a reasonable surgical procedure for spinal extradural arachnoid cysts: Is cyst removal mandatory? Eight consecutive cases and a review of the literature. Acta Neurochir (Wien) 154:1219-1227, 2012

7. Miyakoshi N, Hongo M, Kasukawa Y, Shimada Y: Huge thoracolumbar extradural arachnoid cyst excised by recapping T-saw laminoplasty. Spine J 10:e14-e18, 2010

8. Morizane K, Fujibayashi S, Otsuki B, Sakamoto T, Tsutsumi R, Odate $S$, et al.: Clinical and radiological features of spinal extradural arachnoid cysts: Valve-like mechanism involving the nerve root fiber as a possible cause of cyst expansion. J Orthop Sci 23:464-469, 2018

9. Nabors MW, Pait TG, Byrd EB, Karim NO, Davis DO, Kobrine AI, et al.: Updated assessment and current classification of spinal meningeal cysts. J Neurosurg 68:366-377, 1988

10. Paredes I, Munarriz PM, Toldos O, Castaño-León AM, Panero I, Eiriz C, et al.: True dural spinal epidural cysts: Report of 5 cases. World Neurosurg 135:87-95, 2020

11. Sangala JR, Uribe JS, Park P, Martinez C, Vale FL: Nerve root prolapse into a spinal arachnoid cyst--an unusual cause of radiculopathy. Clin Neurol Neurosurg 111:460-464, 2009

12. Ying GY, Chang KS, Tang YJ, Cheng CY, Zhu YJ, Chen CM: Utilizing real-time contrast medium to detect the fistula of giant spinal arachnoid cyst and treat with minimal invasive surgery. BMC Surg 19:11, 2019 